\title{
Numerical Simulation of Predicting Wear Sites Distributions of Inlet Impingement Plate and Shell Wall of Feedwater Heater

\author{
Xiao-Xin CHEN ${ }^{1, a,{ }^{*},}$ Jian-Qun XU ${ }^{1, b}$ and Wei-Li JIANG ${ }^{1, c}$ \\ ${ }^{1}$ School of Energy and Environment, Southeast University, Nanjing, China \\ *Xiao-Xin Chen
}

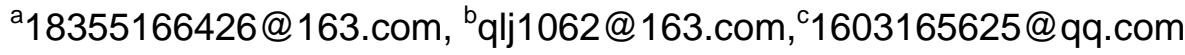
Keywords: Feedwater heater; two phase erosion; wall thinning indicator; wear sites; inlet
impingement plate

\begin{abstract}
Based on the three-dimensional physical model of shell and tube heat exchanger, by means of computational fluid dynamics (CFD) software, the RANS k-Epsilon turbulent model and the Mixture model were adopted to simulate the flow properties and heat transfer in the shell side. And the reliability of the numerical model is verified, which can be further used to explore the possible wear sites on the shell wall and impingement plate of heater. The appropriate indicator derived from the impingement erosion model is obtained. The normal velocity on impingement plate varies with inlet water volume fraction and unit load are simulated, respectively. The results show that the proposed 3-dimensional numerical simulation model considering the impingement erosion model can predict possible wear sites on shell wall of heater. Both the plant measured wear sites and predicted ones show a good agreement, thus provides the theoretical support for the safety and economic operation of feedwater heater.
\end{abstract}

\section{Introduction}

High-pressure heater is an important part of the heat regenerative system, and it will affect the economical operation of whole unit if the high-pressure heater fails. In recent years, the development of computational fluid dynamics (CFD) and the increasing popularization of commercial software CFD have provided a powerful means for studying the effect of heat transfer intuitively under abnormal conditions.

During the practical production, the heater will face many operating conditions that deviate from the design conditions, which will affect the heat transfer effect and flow stability seriously. There are relatively less numerical studies on wear sites distribution of inlet impingement [1] and shell wall [2] of feedwater heater. Based on previous research, the CFD software characterized by lower cost and high visual degree are used to simulate variable conditions of heater. It can predict the heat transfer properties and flowability accurately on the shell side of the heater, providing a reference for optimizing the structure of the feedwater heater and modifying the performance of the existing feedwater heater.

\section{Numerical Modeling of Heater}

\section{Physical Objects and Simplified Conditions}

In this paper, \#2 high pressure heater of a $660 \mathrm{MW}$ ultra-supercritical intermediate reheat unit are taken as the research object, considering the complex geometry characteristics and superior hydrophobicity of \#2 heater, which can make the results more representative compared with others. There are four baffles and five baffles are installed in superheated steam cooling section and drains section respectively, as shown in Fig. 1.The impingement plate is installed in steam inlet to avoid corrosion directly for tubes.

Considering the actual tubes of heaters is huge, in order to make the numerical modeling process smoothly and reduce time cost of numerical calculation, this paper simplifies the research object under the condition that the basic flow parameters and the structure of the heater are basically the 
same. The simplified heater parameters are shown in Tab. 1.

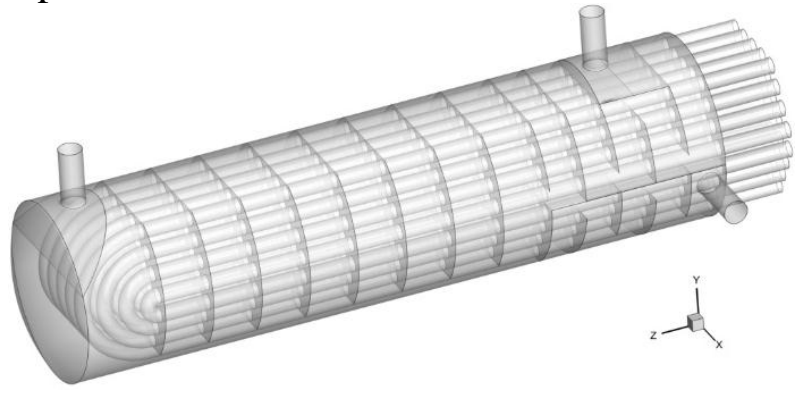

Fig. 1 Schematic presentation of a typical three-zone FWH

Table 1 Structure and parameter of simplified FWH

\begin{tabular}{ccccc}
\hline Parameter & Unit & Superheated & Condensing & $\begin{array}{c}\text { Drain } \\
\text { cooler }\end{array}$ \\
\hline Shell side volume & $\mathrm{cm}^{3}$ & 1359.6 & 7850.1 & 1359.6 \\
Tube side volume & $\mathrm{cm}^{3}$ & 930.3 & 4676 & 930.3 \\
Heat transfer area & $\mathrm{cm}^{2}$ & 2345.7 & 11818.2 & 2345.7 \\
Tube number & & & 26 & \\
Tube diameter & $\mathrm{mm}$ & & 16 & \\
Tube pitch & $\mathrm{mm}$ & & 21 & \\
\hline
\end{tabular}

\section{Numerical Simulation Method}

ANSYS 14.5 is used to complete the numerical calculation [3], Reynolds-average d Navier-Stokes (RANS) turbulent flow model and Bousinesq assumption are adopted to simulate the internal flow of the heater, namely, the k-Epsilon model and the Scalable wall function. The phase change in condensing sections uses the Mixture model [4].

\section{Impingement Wear Model}

$$
m=C_{S} N F(\theta) \frac{\rho u_{n}^{2}}{H V}
$$

Where $\rho$ is density, $u_{n}$ is velocity, $\mathrm{m}$ is wear rate, $\mathrm{C}_{\mathrm{s}}$ denotes system constant, and $\mathrm{N}$ is frequency, $\mathrm{F}(\theta)$ is characteristic function. It is obvious that the metal loss is proportional to the density of the liquid droplets and the square of their normal velocity. Thus, $\rho u_{n}{ }^{2}$ is an appropriate indicator [5] to predict the wear sites on the impingement plate.

\section{Numerical Simulations on Inlet Baffle}

In order to avoid steam scour the heat transfer tubes directly and the distribution of the working fluid uneven on the shell side, the impingement baffle [6] is provided at steam inlet of high pressure heater, the steam inlet of low pressure heater and the superior drain inlet. In actual operation, corrosion of inlet baffle was caused by scouring of high temperature and high pressure fluids[7], threatens the safety and stability of the heater operation seriously, especially in the event of sudden changes and the two-phase flow inlet, therefore detailed simulation analysis of corrosion of inlet baffle is needed.

\section{Steam Inlet Baffle}

When steam extraction is a vapor-liquid two-phase flow, the two-phase fluid hits the side wall of the baffle or shell, which is prone to flow accelerated corrosion. According to the literature [8], the rate of thinning of the metal after being impacted by the vapor-liquid two-phase flow is similar to the normal velocity distribution of the normal velocity of the collision wall of the working fluid, and is 
proportional to $\rho u_{n}{ }^{2}$. Based on the mass flow rate of imported working fluids in the original rated conditions, the inlet water volume fraction $V F w$ was set to $0.0005,0.0025$ and 0.005 , respectively. The simulation results are shown in Figure 2.

The normal velocity of the water on the impingement plate is larger at the location directly below the steam inlet and decreases with water volume fraction increasing. The volumetric flow rate is reduced, so the overall speed is reduced, which also leads to a reduction in the water phase velocity. However, the distribution of the right column $\rho u_{n}^{2}$ shows that the corrosion rate increases with the increase of the inlet water content.
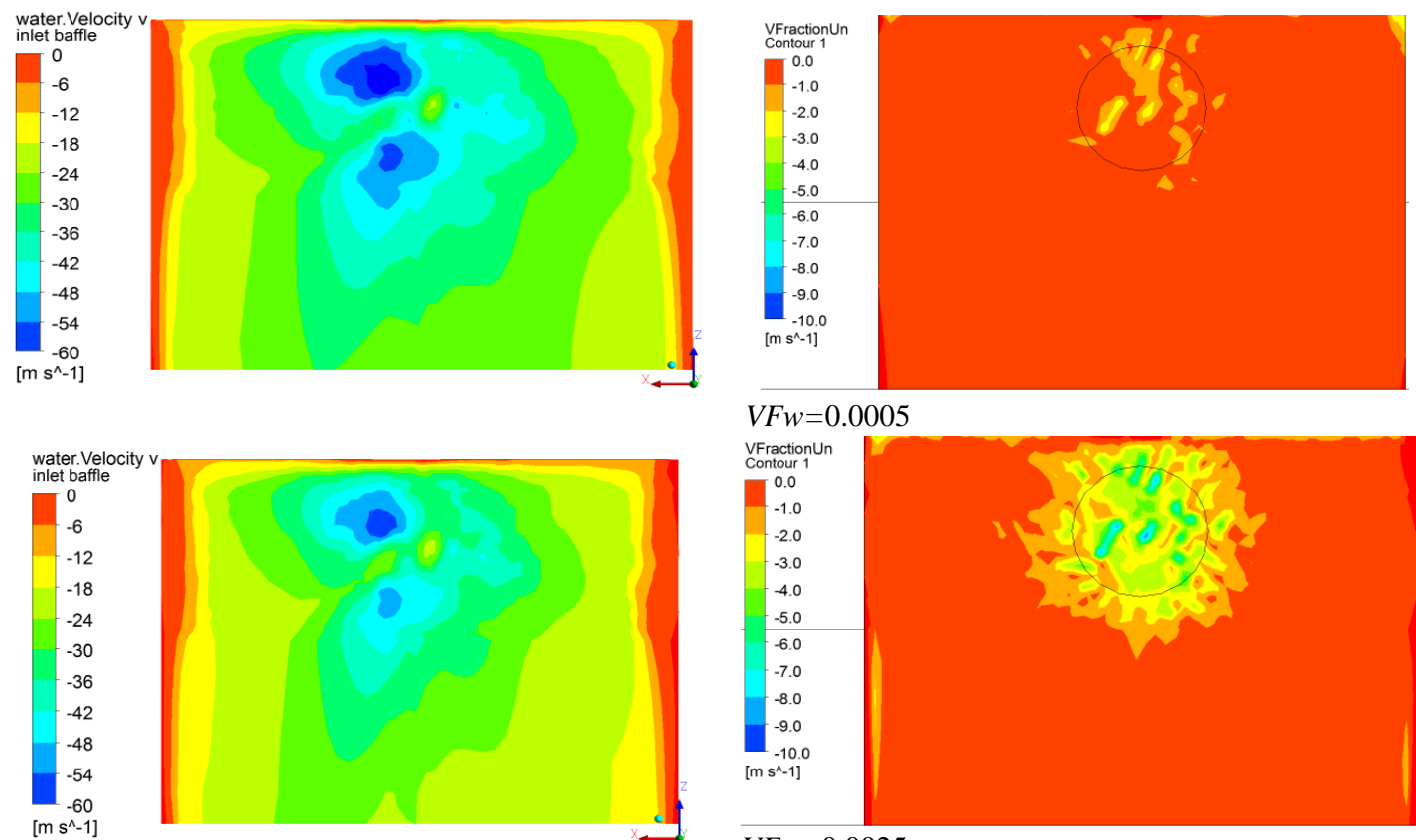

$V F w=0.0025$
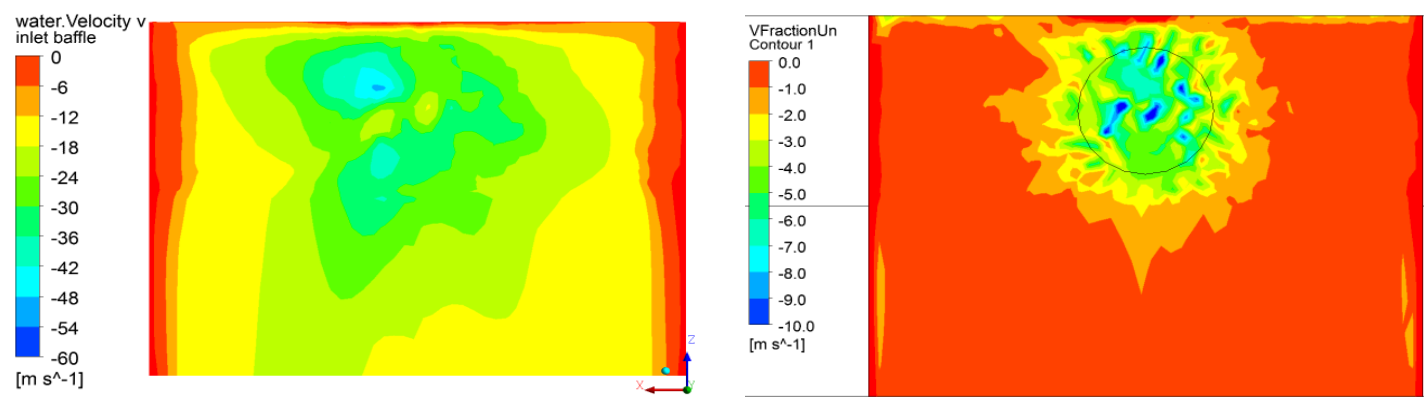

$V F w=0.005$

Fig. 2 Distribution of $u_{n}$ and $\rho u_{n}{ }^{2}$ near impingement plate in different water volume fraction

From Fig.3, it can be seen that the location where the shell is prone to flow accelerated corrosion is located immediately above the upper baffle; and the location where the flow accelerated corrosion is likely to occur on the inlet anti-shock plate. It is just below and slightly above the steam inlet. 

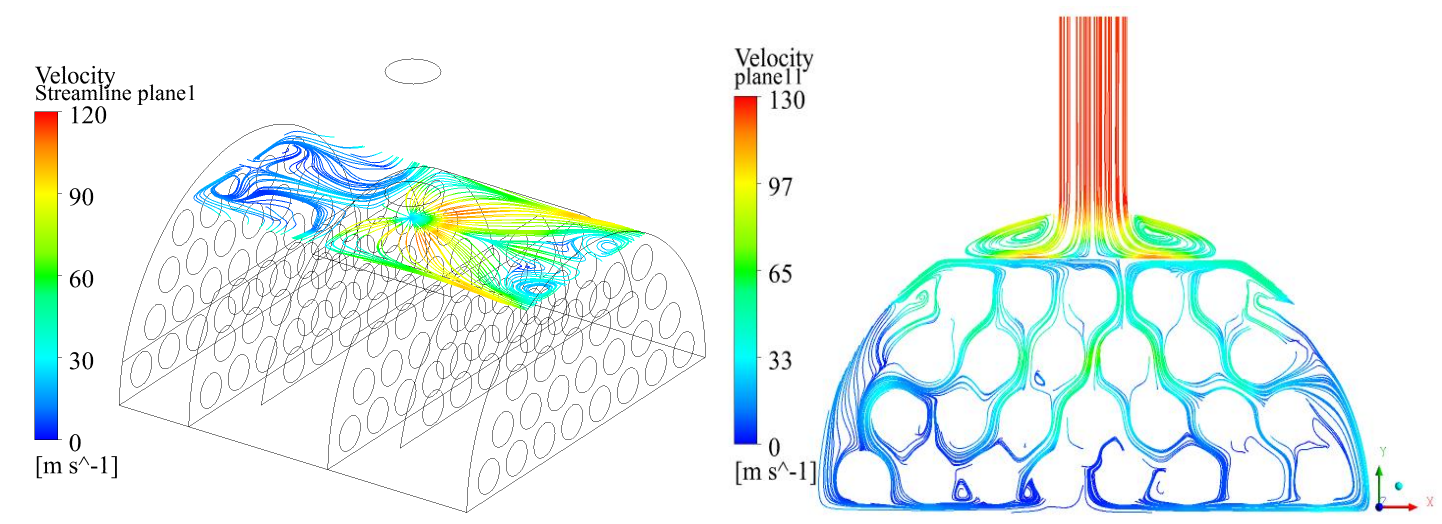

Fig. 3 Streamline of inlet impingement plate

\section{Drain Inlet Baffle}

In addition, the drain inlet baffle was also simulated [9] under different operating conditions. The normal velocity of the working medium is still shown here, as shown in Fig.4. It can be seen that the velocity of the working fluid at the lower edge of the baffle plate is relatively large. This is because the flow of the working fluid with a small portion of the coagulation flow is diffused. The flow rate of the working fluid in the coagulation stage is much larger than that at the hydrophobic inlet of the upper stage, so the flow velocity is fast. However, in most areas of the upper hydrophobic baffle, as the load decreases, the flow rate of the working fluid decreases, and the flow rate of the working fluid decreases. With regard to the overall trend of the flow distribution, the upper flow velocity of the baffle is smaller than the flow velocity of the lower baffle.

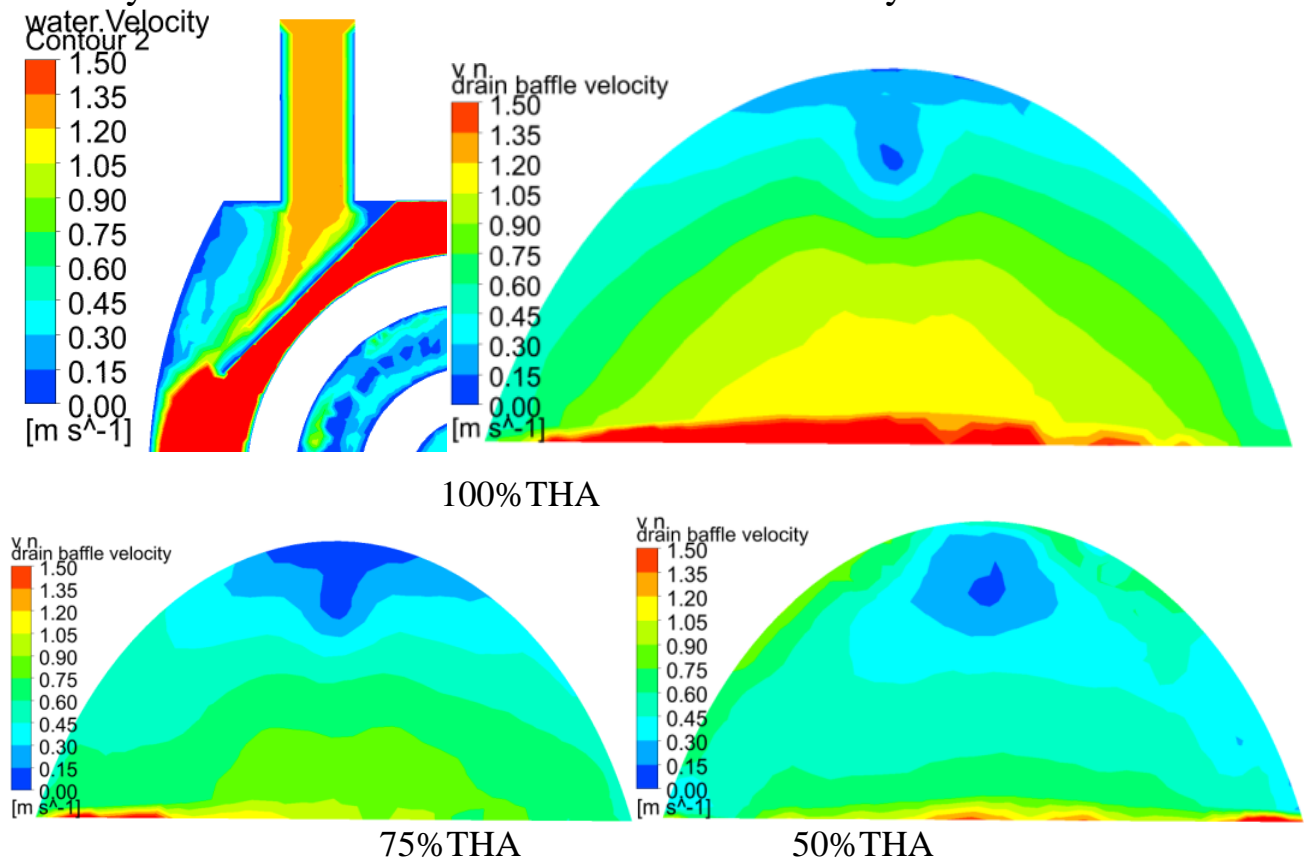

Fig. 4 Water volume fraction in hydrophobic baffle

From Fig.5, it can be found that the distribution of the water phase on the upper hydrophobic baffle. It can be seen from the figure that when the load is high, except for the lower edge, the working fluid on the baffle is basically water. As the load decreases, vapor phase gradually appears on the edge of the baffle, as shown in the figure. The 75\% THA operating conditions, when the load is reduced to 50\% THA vaporization phenomenon has been very obvious. The lower the visible load, the easier flow accelerated corrosion. 


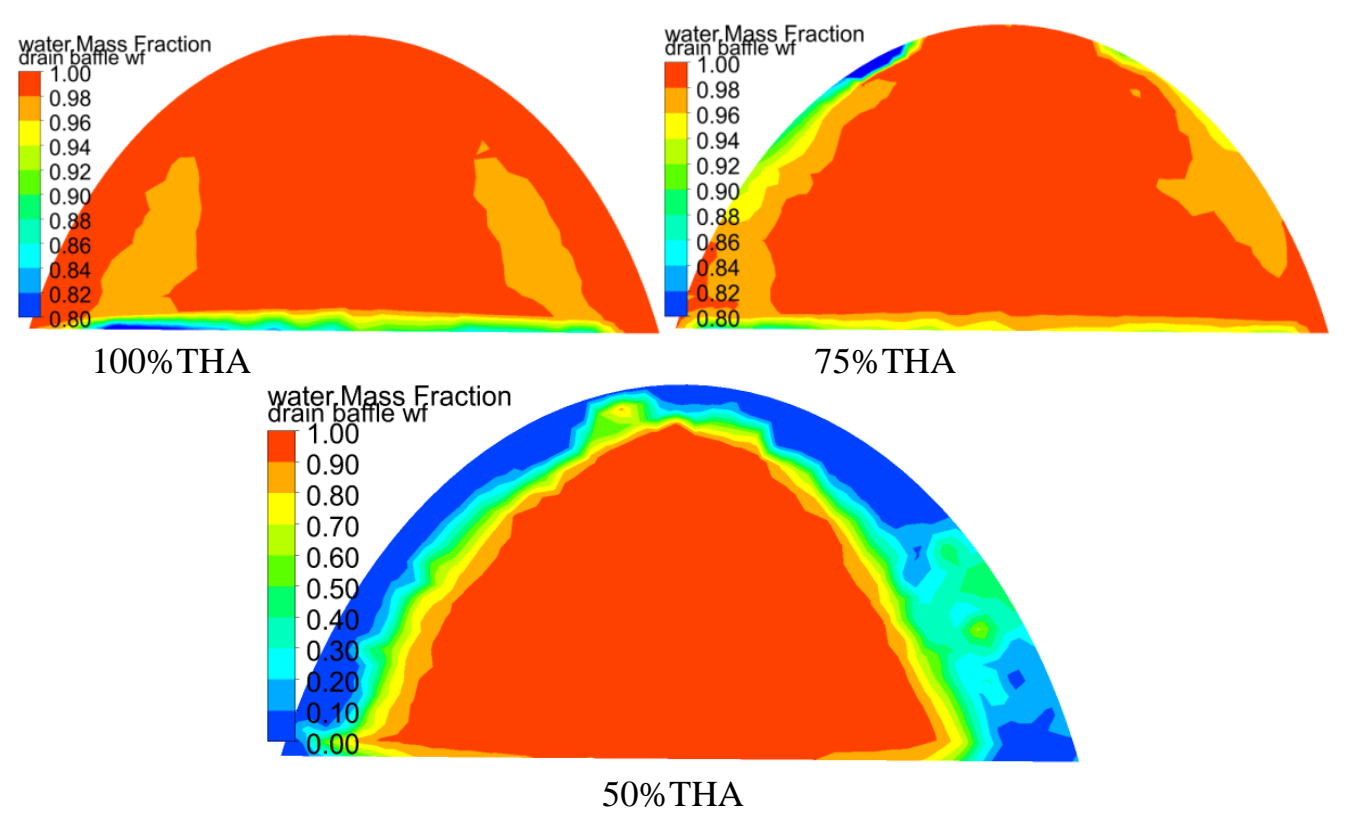

Fig. 5 Water volume fraction in hydrophobic baffle

It can be seen that when the working fluid parameters are low, the inlet drain baffle will withstand more severe vapor-liquid two-phase flow conditions. Not only including lower unit load but also lower pressure heaters under higher unit load.

\section{Conclusions}

The three-section feedwater heater of the regenerative system are taken as the research object, the visualized distribution of wear sites near impingement plate, shell wall of feedwater heater and drain baffle were obtained based on three-dimensional numerical simulation. The numerical simulation results are as followings:

(1) The droplet impingement model is established, and $\rho u_{n}{ }^{2}$ are taken as an indicator to predict reasonably wear sites on impingement plate, it is founded that the wear sites are distributed on shell wall near impingement plate and the baffle directly below the steam inlet.

(2) The influence of inlet water volume fraction on wear sites distributions of feedwater heater within $V F w=0.0005 \sim 0.005$ are obtained, the finding reveals that the wear severity is strongly related to the inlet water volume fraction of feedwater heater, and wear severity increases with the increase of the inlet water volume fraction.

(3) The influence of inlet water volume fraction on drain inlet baffle is similar to steam inlet impingement plate. And the lower the unit load, the easier the flow accelerated corrosion.

(4) The numerical results can be effectively utilized for local shell wall thinning control and for design improvements to prevent feedwater heater damage. According to predicting wear sites distribution of feedwater heater, can take measures to reduce loss including corrosion resistant materials.

\section{References}

[1] KIM K H, KIM H J. Design modification of a feedwater heater impingement baffle to mitigate shell wall thinning by flow acceleration corrosion [J]. Nuclear Engineering \& Design, 2013, 262(9):409-417.

[2] HWANG K M, WOO L, JIN T E, et al. A study on the shell wall thinning causes identified through experiment, numerical analysis and ultrasonic test of high-pressure feedwater heater [J]. Nuclear Engineering and Design, 2008, 238(1):25-32.

[3] ANSYS. ANSYS Help [Z]. 2009. 
[4] Li J, Chen J, Pu H, et al. Simulation of falling film flow and heat transfer at shell-side of coil-wound heat exchanger [J]. CIESC Journal, 2015, 66(s2):40-49.

[5] FERNG Y M, Hung C T. Predicting distributions of wear sites on shell wall of feedwater heater in nuclear power plant using two phase models[J]. Energy Conversion \& Management, 2008, 49(5):1182-1192.

[6] Liu X, Wang Y, Chang Y, et al. Simulation and analysis of impingement plate in tube channel in one tube side heat exchanger [J]. Process Equipment and Piping, 2016, 53(4):41-43.

[7] Wen H. Study of design method and numerical simulation for shell-and-tube heat exchanger [D]. East China University of Science and Technology, 2012.

[8] Hwang K M, Woo L, Jin T E, et al. A study on the shell wall thinning causes identified through experiment, numerical analysis and ultrasonic test of high-pressure feedwater heater $[\mathrm{J}]$. Nuclear Engineering and Design, 2008, 238(1):25-32.

[9] Jiang W. Performance analysis and numerical simulation of heat exchanges in steam turbine unit thermal system [D]. Southeast University, 2015. 